In this experiment with hops the results suggest that, provided light intensity (sunshine) during a 14.5-h day is adequate, assimilates produced allow the bine to elongate for the whole of the diurnal cycle at a rate determined by air temperature only. When light intensity falls too low the quantity produced does not suffice and stem elongation commences to slow down during the following night.

Hop Research Station,

R. H. J. Roвorgh

Riwaka, Nelson,

New Zealand.

${ }^{1}$ Thut, H. F., and Loomis, W. E., Plant Physiol., 19, 114 (1944).

\section{Variated Leaf Shape of Infected Plants of Samanea saman (Jacqu.) Merr.}

DURING the past few years, rain trees (Samanea saman (Jacqu.) Merr.) in and about Calcutta are dying in numbers. Some of these trees growing in the Indian Botanic Garden, Calcutta, were found heavily infected by lac insects, Laccifer lacca (Kerr). Infected branches of these plants bear highly pinnate leaves. The shape, size, number and thickness of leaflets in individual leaves of infected plants are markedly different from those of normal plants (Figs. 1 and 2). The size and appearance of complete leaves in infected plants are also different from those in normal plants. Usually the leaflets in infected plants are of different degrees of ovate shape with variously acute opposite ends. The normal leaflets are broadly

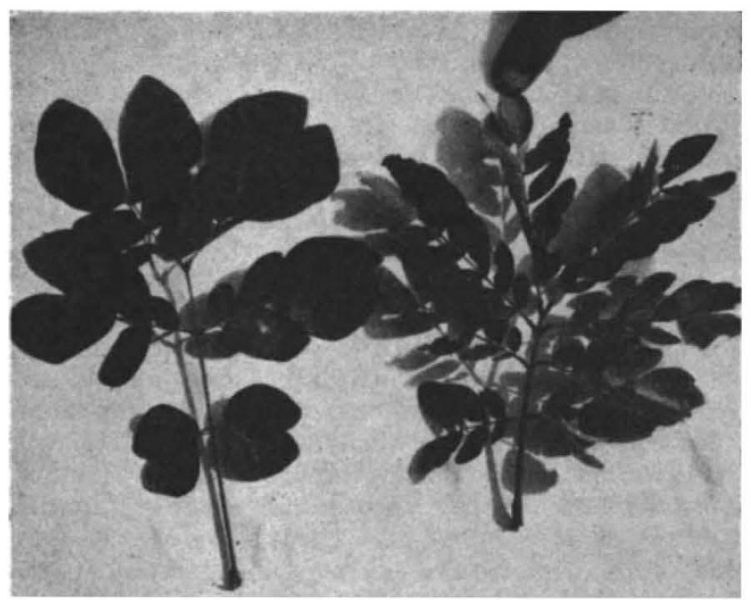

Fig. 1. J,eft, normal leaf; right, infected leaf

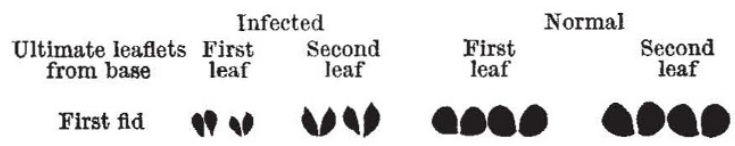

Second fld UV VV O०00

Third fld UIV ve 00000

Fourth fid 4W uv 000000

Fifth fid

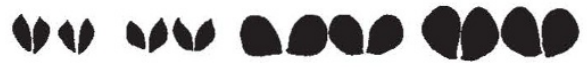

Sixth fld

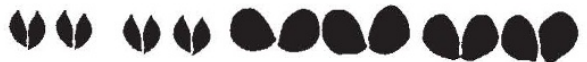

Fig. 2 obovate to very broadly obovate. For describing these leaflets, the terminologies proposed by the Systematics Association Committee ${ }^{1}$ have been used.

The present ideas on leaf shape variabilities and their probable causes have been reviewed by Ashby ${ }^{2}$, Wardlaw ${ }^{3}$. Jones ${ }^{4}$ and others. Among others, the calcium/ potassium balance, light intensity and length of the day are considered as important factors affecting leaf-shape. These factors are related to metabolism and nutrition, which control plant growth. In the case recorded here the infected plants bearing variable leaflets under investigation grow adjacent to uninfected plants with normal leaves, which may be treated as control, at least under apparently similar conditions. It therefore appears that lac infection somehow upsets the nutrition balance of their host plants. As a result variation in leaf shap9 occurs. Experiments are now in progress with variously starved saplings of rain tree under controlled conditions with a view to find out the nature of nutritional deficiency which may result in leaf-shape variabilities, as reported here.

J. SEN

S. K. BASU

Indian Botanic Garden, Howrah, Calcutta.

${ }^{1}$ Systematics Association Committee for Descriptive Biological Terminology II, Terminology of Simple Symmetrical Plane Shapes (Chart 1), Taxon, II, Terminology

${ }^{2}$ Ashby, E., New Phytol., 47, 153 (1948).

${ }^{3}$ Wardlaw, C. W., Phylogeny and Morphogenesis (Macmillan and Co., Ltd. London, 1952).

4 Jones, H., in The Growth of Leaves, edit. by Milthorpe, F. L., 93 (Butterworth Sci. Publ., London, 1956).

\section{Rod-shaped Particles in Saprospira}

FIVE strains of Saprospira grandis Gross, an apochlorotic cyanophyte or flexibacterium, have been isolated in pure culture from several marine littoral habitats around the United States ${ }^{1}$. In all strains the filaments tend to fragment and the individual cells to lyse at the end of the growing period. For example, a $10-\mathrm{ml}$. culture in a $50-\mathrm{ml}$. flask, grown in a sea-water medium containing $5 \mathrm{~g} / \mathrm{l}$. tryptone and $5 \mathrm{~g} / \mathrm{l}$. yeast extract (Difco) and shaken gently but constantly at $30^{\circ}$, forms within 1-2 days after inoculation a dense peach-coloured suspension with a satiny sheen ; under the microscope it is seen to be full of helical filaments. A day or two later the sheen disappears, the colour becomes duller, and no microscopically intact or viable cells remain.

Spontaneous lysates obtained in this way contain large numbers of rod-shaped particles which, though submicroscopic, are readily revealed by electron microscopy even without elaborate procedures of differential centrifugation. Each cell evidently liberates some hundreds of these particles, which may reach a density of $10^{10}$ per ml. in the crude lysate (Figs. 1 and 2). Two types can be distinguished : $A$, apparently hollow rods, $200 \times 30 \mathrm{~m} \mu$ (Fig. 3) ; $B$, apparently solid rods of the same dimensions, but each furnished at one end with a tail about $300 \mathrm{~m} \mu$ long (Fig. 3). It is estimated that less than 10 per cent of the rods are of the latter type.

Chemical analyses by Correll $^{2}$ indicate that these particles are largely ribonucleoprotein, containing RNA and protein in the ratio of approx. 1:2. Their RNA content is thus considerably higher than that found in tobacco-mosaic virus (about 1:15), with which the particles show some superficial resemblance. However, there is no evidence yet to indicate that these particles are pathogenic; they have been found naturally present in lysates of all five strains of $S$. grandis so far examined. Similar particles have also been found in lysates of another marine flexibacterium, to be described elsewhere. Two, clearly of the same size and form, appear by chance in an electron micrograph of a phage lysate of Chondrococcus columnaris ${ }^{3}$, a related freshwater flexibacterium. 